\title{
Treatment of gingival recession with collagen membrane and DFDBA: a histometric study in dogs
}

\section{Elizabeth Pimentel Rosetti(a) Rosemary Adriana Chiérici Marcantonio(b) Joni Augusto Cirelli(b) Elizangela Partata Zuza ${ }^{(a)}$ Elcio Marcantonio Jr ${ }^{(b)}$}

(a) $\mathrm{PhD}$, Professor of Periodontics, School of Dentistry, Educational Foundation of Barretos (UNIFEB), Barretos, SP, Brazil.

(b) PhD, Professor of Periodontics, School of Dentistry of Araraquara, São Paulo State University (UNESP), Araraquara, SP, Brazil.
Corresponding author:

Elizangela Partata Zuza

Rua Buarque, 67, Campos Eliseos

Ribeirão Preto - SP - Brazil

CEP: 14080-530

E-mail: elizangelazuza@yahoo.com.br
Received for publication on Jun 13, 2008 Accepted for publication on Nov 05, 2008

\begin{abstract}
In a previous study, we evaluated the findings related to the use of resorbable collagen membranes in humans along with DFDBA (demineralized freeze-dried bone allograft). The aim of this subsequent study was to histometrically evaluate in dogs, the healing response of gingival recessions treated with collagen membrane + DFDBA (Guided Tissue Regeneration, GTR) compared to a coronally positioned flap (CPF). Two types of treatment were randomly carried out in a split-mouth study. Group 1 was considered as test (GTR: collagen membrane + DFDBA), whereas Group 2 stood for the control (only CPF). The dogs were given chemical bacterial plaque control with $0.2 \%$ chlorhexidine digluconate during a 90-day repair period. Afterwards, the animals were killed to obtain biopsies and histometric evaluation of the process of cementum and bone formation, epithelial migration and gingival level. A statistically significant difference was found between groups with a larger extension of neoformed cementum $(\mathrm{GTR}=32.72 \% ; \mathrm{CPF}=18.82 \% ; \mathrm{p}=0.0004)$, new bone $(\mathrm{GTR}=23.20 \% ; \mathrm{CPF}=09.90 \% ; \mathrm{p}=0.0401)$ and with a smaller area of residual gingival recession in the test group $(\mathrm{GTR}=50.69 \%$; $\mathrm{CPF}=59.73 \% ; \mathrm{p}=0.0055)$ compared to the control group. The only item assessed that showed no statistical difference was epithelial proliferation on the root surface, with means of $15.14 \%$ for the GTR group and $20.34 \%$ for the CPF group ( $\mathrm{p}=0.0890)$. Within the limits of this study we concluded that the treatment of gingival recession defects with GTR, associating collagen membrane with DFDBA, showed better outcomes in terms of a larger extension of neoformed cementum and bone, as well as in terms of a smaller proportion of residual recessions.
\end{abstract}

Descriptors: Gingival recession; Guided tissue regeneration; Reconstructive surgical procedures; Histology, comparative. 


\section{Introduction}

Physical barriers (membranes) have been used in periodontal defects in order to provide Guided Tissue Regeneration (GTR). The GTR technique has shown to be a viable alternative when compared to other root coverage techniques used for gingival recessions (free gingival graft, repositioned flaps, and connective tissue grafts). This technique does not use donor tissue from other areas of the mouth, ${ }^{1}$ and it has been demonstrating an ability for histological regeneration. ${ }^{2}$ Several studies have been conducted to evaluate the efficiency of the GTR procedure to treat gingival recessions. ${ }^{3-10}$ Some other studies have also assessed histological periodontal regeneration, using or not resorbable membranes as barriers. ${ }^{2,11-18}$

Some clinical studies evaluated the combined use of membrane and bone graft in dehiscences; $;^{19-23}$ however, there is still a lack of histological studies that evaluate the regenerative outcomes of the GTR procedure with the use of both membrane and bone graft. ${ }^{13}$ Rosetti et al. ${ }^{22}$ (2000) evaluated the clinical results of the association between membrane and DFDBA (demineralized freeze-dried bone allograft) in humans. Thus, the purpose of this subsequent study was to evaluate the healing response of gingival recession treated with collagen membrane and DFDBA by means of histometrical assessment in dogs.

\section{Material and Methods}

This study was approved by the Ethics Committee in Animal Research of Araraquara Dental School - "Júlio de Mesquita Filho". Five male dogs were used with mean ages between 1.5 and 3 years, and weighing between 12 and $18 \mathrm{~kg}$. The animals were healthy and showed no periodontal disease or gingival recession in the initial clinical and radiographic examination. Using a split-mouth design, two maxillary cuspids (canines) were randomly chosen from each animal, totaling 10 teeth. Thus, one of the sides received the test treatment, and the opposite side served as the control treatment.

\section{Defect creation and chronification}

The anesthetic procedure included previous sedation with intramuscular injection of dihydrothiazine
(4 mg/kg), followed by general anesthesia induction through intravenous injection of sodium thiopental $(12 \mathrm{mg} / \mathrm{kg})$. The local anesthesia was carried out through infiltrative technique with $2 \%$ lidocaine (1:100.000 of noradrenalin).

Mucoperiosteal flaps were performed and the bone tissue was removed with rotary instruments and Ochsenbein's microchisel in order to create defects and buccal recessions as described by Cortellini et al. ${ }^{4}$ (1991). Hence, the defects showed a vertical height of $7 \mathrm{~mm}$ (from the cementoenamel junction to the bone crest), and a horizontal width of $5 \mathrm{~mm}$ (in the cementoenamel junction).

The roots were scaled with Gracey 7-8 periodontal curettes (Neumar, São Paulo, SP, Brazil) in order to remove periodontal ligament fibers and cementum. Next, a metallic matrix was fixed on the root for defect chronification. ${ }^{24}$ The flaps were sutured with 4.0 silk (Silk suture, Johnson \& Johnson, São Paulo, SP, Brazil), which was removed after 7 days under general anesthesia. During the 60-day chronification period, the dogs were fed only with water and soft rations in order to provide increased plaque accumulation and to develop chronic inflammatory response.

After the chronification period the matrixes were removed, the areas scaled, and prophylaxis was carried out with a rubber cup. Chemical bacterial plaque control was performed daily (5 times/week) with topical application of a $0.2 \%$ chlorhexidine solution (Periogard ${ }^{\circledR}$, Colgate-Palmolive, São Paulo, SP, Brazil).

\section{Defect treatment}

Approximately 2 weeks after the chronification period, the dogs were anesthetized to perform the mucoperiosteal flaps (oblique incisions) and defect reassessment. The defects were debrided and the roots scaled with Gracey 7-8 periodontal curettes (Neumar, São Paulo, SP, Brazil). Then, marks (notches) were made on the defect in the most apical region in the cementoenamel junction with a half (\# $1 / 2$ ) round bur at low speed. The root surfaces were conditioned with a tetracycline hydrochloride solution (Farmácia Santa Paula, Araraquara, SP, Brazil) that was prepared immediately before being used 
at a concentration of $125 \mathrm{mg} / \mathrm{ml}$. The solution was rubbed for 3 minutes with cotton pellets, which were changed every 30 seconds. Then, the roots were irrigated with distilled water for 20 seconds.

At this stage, the defects were randomly treated according to the following groups:

- GTR: the teeth received bioabsorbable collagen membrane (Universidade de São Paulo, São Carlos, SP, Brazil $)^{25}$ and demineralized freeze-dried bone allograft (DFDBA, Dembone, Pacific Coast Tissue Bank, 93-195/254-48). The membranes overlapped the bone defects at least $3 \mathrm{~mm}$ and were sutured to the tooth. DFDBAs were used to maintain the space between the root and the membrane. The flaps were positioned coronally and sutured with an interrupted sling suture with 4.0 silk (Silk suture, Johnson \& Johnson, São Paulo, SP, Brazil).

- CPF: Coronally positioned flap (CPF) was used alone.

At the end of the surgeries, the dogs received intramuscular injection of antibiotic (Penicillin G benzatin - $40.000 \mathrm{UI} / \mathrm{kg}$ ) and analgesic (Dipyrone $2 \mathrm{ml} / 10 \mathrm{~kg}$ ) as post-operative medications. After 10 days, the animals were anesthetized to remove the sutures.

The dogs were observed for a period of 90 days, and, throughout this time, they were fed with water and soft rations in order to minimize mechanical injuries to the soft tissues. The dogs also received daily a chemical bacterial plaque control through topical application of $0.2 \%$ chlorhexidine gel (Farmácia Santa Paula, Araraquara, SP, Brazil).

\section{Animal killing and histological processing}

After a repair period (90 days), the dogs were sedated with dihydrothiazine and killed with a Sodium Thiopental overdose (Abbott Laboratórios do Brazil Ltda., São Paulo, SP, Brazil). The biopsies were harvested, fixed in $10 \%$ formalin and decalcified in Morse solution $50 \%$ formic acid and $20 \%$ sodium citrate, ratio 1:1) for approximately 4 months (solution changed every 2 days). Routine histological processing and paraffin immersion were performed. Series-sections with thickness of $5 \mu \mathrm{m}$ were cut along the bucco-lingual plane using a Jung
Supercut 2065 automatic microtome (Leica Instruments Gmbh, Heldelberg, Germany). Three sections of each tooth were selected to be assessed under optical microscopy.

\section{Histometric assessment}

The sections were stained with Hematoxilin - Eosin (H\&E) and Massom tricrome for the histometric evaluation, and they were codified in regards to the experimental groups. A computer with a system of image assessment was used, and an optical microscope Diastar (Cambridge Instruments, Buffalo, NY, USA) was coupled to a video camera DXC107A/107AP (Sony Eletronics Inc., Tokyo, Japan), which was connected to a microcomputer with image assessment software (Sigma Proscan, Jandel Scientific, San Rafael, CA, USA). The sections of the images selected through optical microscopy were captured by the video camera and digitized to the microcomputer. Thus, linear measurements were performed. The following variables were analyzed (Figure 1):

A. Level of epithelium: distance from the gingiva crest until the apical region of the epithelial tissue (sulcular + junctional).

B. Cementum Formation: distance from the apical notch to the coronary region of the neoformed cementum.

C. Bone Formation: distance from the apical notch to the coronary region of neoformed tissue.

D. Residual Gingiva Recession: linear extension of roots covered by no tissue, measured from the gingiva margin to the coronal notch.

After the measurements of the five sections, a mean was derived for each parameter. To obtain means of each parameter, the measurements were carried out at three different moments. The statistical analysis used Mann-Whitney's test. The null hypothesis was considered when there was no difference between the two treatment modalities and the rejection of this hypothesis was accepted when $\mathrm{p}<0.05$.

\section{Results}

There was a statistically significant difference between the groups represented by a larger extension of neoformed cementum (GTR $=32.72 \%$; 


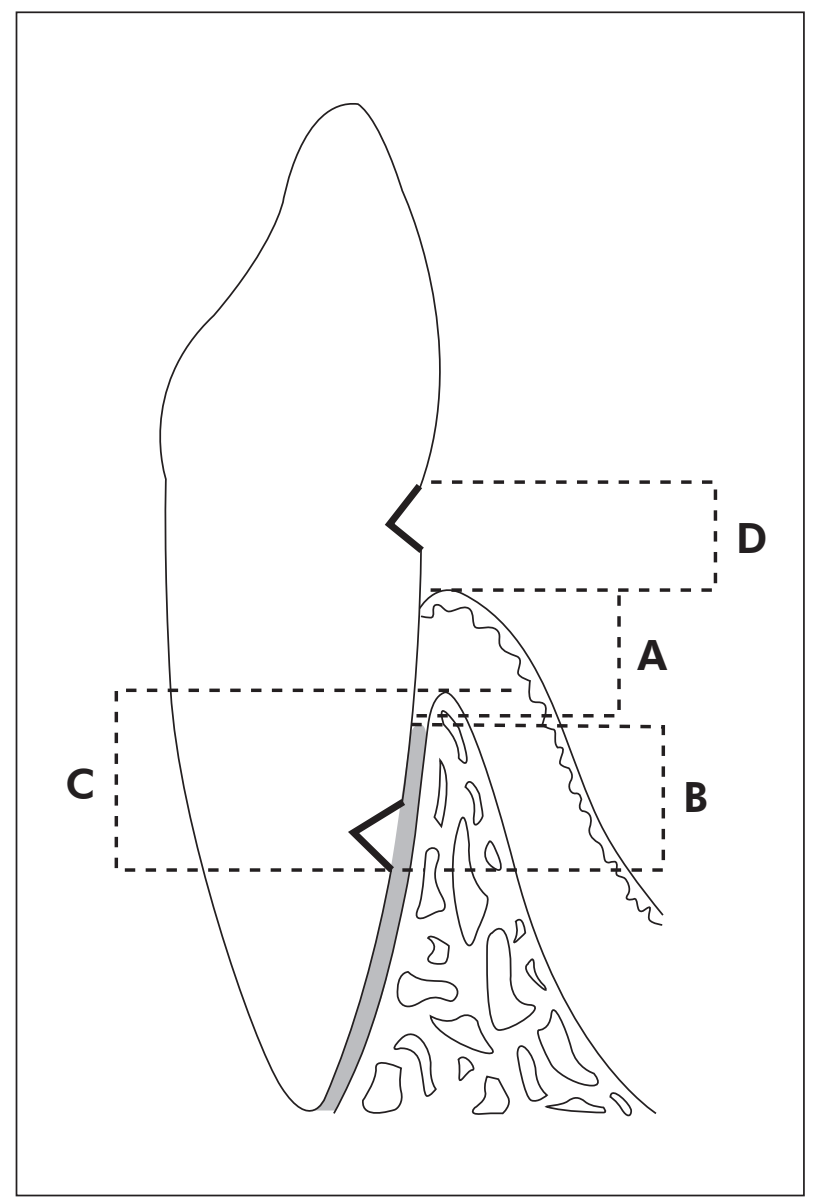

Figure 1 - Linear measurement settings (cross-sectional plane).

$\mathrm{CPF}=18.82 \% ; \quad \mathrm{p}=0.0004), \quad$ new bone $(\mathrm{GTR}=23.20 \% ; \mathrm{CPF}=9.90 \% ; \mathrm{p}=0.0401)$ and $\mathrm{a}$ smaller extension of residual gingival recession in the test group (GTR $=50.69 \%$ ) when compared to the control group $(\mathrm{CPF}=59.73 \%)$, with $\mathrm{p}=0.0055$ (Table 1).

The only item that showed no statistical difference during the assessment was the proliferation of the epithelium (sulcular and junctional) on the root surface, with averages of $15.14 \%$ for the GTR group and $20.34 \%$ for the CPF group ( $\mathrm{p}=0.0890$ ).

The neoformation of bone occurred closer to the apical notch due to osteoblastic cell migration towards this region.

\section{Discussion}

Kimble et al. ${ }^{21}$ (2004) showed no significantly different clinical results between the test (membrane and DFDBA) and control (membrane alone) groups; nevertheless, other studies ${ }^{19,23}$ reported that the use of this combination can bring additional clinical benefits, such as higher percentage of root coverage, increased clinical insertion and keratinized gingiva.

The literature presents clinical studies on gingival recessions that do or do not associate the use of bioabsorbable membranes with bone grafts; $;^{19-23}$ however, most of the histological research evaluated the use of membranes alone..$^{2,11-18}$ To provide further information on the clinical benefits mentioned in previous studies ${ }^{22}$ the association of collagen membranes with DFDBA was chosen in order to assess the histometrical healing response and because there is a lack of research evaluating the regenerative process by means of microscopy, evaluating factors such as epithelial proliferation, cementum and bone formation, as well as residual recessions of the gingival margin.

According to Bowers et al. ${ }^{11}$ (1989), the chances of regeneration are improved when DFDBA is combined with GTR treatment. These authors have observed that periodontal defects treated with homogenous bone showed a greater bone filling and cementogenesis when compared to the defects that were only scaled. Our findings confirm that the GTR technique (with bioabsorbable collagen membrane and DFDBA) positively influences periodontal regeneration, but it was not possible to isolate the effect of the membrane or DFDBA because there was not a control group with membrane or DFDBA alone.

The averages of new cementum formation were statistically significant for GTR $(32.72 \%)$ when compared to CPF (18.82\%), as well as bone neoformation with averages of $23.20 \%$ (GTR) and $9.90 \%$ (CPF). This may have occurred due to the exclusion of epithelial cells provided by the membrane, which was efficient in allowing repopulation of the nondifferentiated mesenchymal cells in the region of the periodontal ligament, leading to a considerable regeneration of the tissues lost. ${ }^{26}$

Bone and cementum neoformation was also observed by Lee et al. ${ }^{15}$ (2002), who found that there was a greater bone and cementum formation in the GTR than in the CPF group throughout 16 weeks, although they were not statistically significant. 


\begin{tabular}{|c|c|c|c|c|c|c|}
\hline \multirow{9}{*}{$\begin{array}{r}\text { Table } 1 \text { - Comparison of } \\
\text { histological variables according to } \\
\text { the experimental groups. }\end{array}$} & Variable & Group & Sample (n) & Sections ${ }^{\S}$ & Mean (\%) & $p$ \\
\hline & \multirow{2}{*}{ Epithelium } & GTR & 5 & 15 & 15.14 & \multirow{2}{*}{0.0890} \\
\hline & & CPF & 5 & 15 & 20.34 & \\
\hline & \multirow{2}{*}{ Cementum } & GTR & 5 & 15 & 32.72 & \multirow{2}{*}{$0.0004^{*}$} \\
\hline & & $\mathrm{CPF}$ & 5 & 15 & 18.82 & \\
\hline & \multirow{2}{*}{ New bone } & GTR & 5 & 15 & 23.20 & \multirow{2}{*}{$0.0401^{*}$} \\
\hline & & CPF & 5 & 15 & 09.90 & \\
\hline & \multirow{2}{*}{$\begin{array}{l}\text { Residual } \\
\text { recession }\end{array}$} & GTR & 5 & 15 & 50.69 & \multirow{2}{*}{$0.0055^{*}$} \\
\hline & & $\mathrm{CPF}$ & 5 & 15 & 59.73 & \\
\hline
\end{tabular}

GTR: guided tissue regeneration; CPF: coronally positioned flap; * statistically significant value; ${ }^{\S}$ Three sections for each tooth.

It must be pointed out that the authors used only membranes without bone graft.

Considering the root coverage, the average of residual recession was $50.69 \%$ for the GTR group and $59.73 \%$ for the CPF group, with a statistically significant difference (Mann-Whitney). Although less residual recessions have been observed when the GTR technique was used, the study by Leknes et al. ${ }^{6}$ (2005) showed that the use of bioabsorbable membranes does not seem to improve short- and longterm clinical outcomes, and that CPF offers a simpler treatment approach for Class I and II recessions with similar results compared to GTR. Our results concerning the residual recessions showed discrepancies in relation to other studies because we obtained $50.69 \%$ for the GTR group while Rosetti et al. ${ }^{22}$ (2000) found $15.8 \%$ and Paolantonio ${ }^{7}$ (2002) $18.99 \%$.

The only assessed item that showed no statistical difference during the assessment was epithelial proliferation on the root surface, with averages of

\section{References}

1. Sedon CL, Breault LG, Covington LL, Bishop BG. The subepithelial connective tissue graft: part II. Histologic healing and clinical root coverage. J Contemp Dent Pract. 2005;6(2):13950.

2. Cortellini P, Clauser C, Pini Prato G. Histologic assessment of new attachment following the treatment of a human buccal recession by means of a guided tissue regeneration procedure. J Periodontol. 1993;64(5):387-91.

3. Borghetti A, Glise JM, Monnet-Corti V, Dejou J. Comparative clinical study of a bioabsorbable membrane and subepithelial
$15.14 \%$ for the GTR group and $20.34 \%$ for the CPF group. Nonetheless, even though this item showed no statistical difference, there was a larger epithelial migration on the root surface for the CPF group than for the GTR group, which confirms the barrier property of the membrane.

\section{Conclusion}

Within the limits of this study, it was possible to conclude that the treatment of gingival recession with collagen membrane and DFDBA showed better results than the treatment with Coronally Positioned Flap alone, which was demonstrated by the larger extension of neoformed cementum and bone, as well as by a smaller proportion of residual recessions.

\section{Acknowledgements}

The authors would like to express their gratitude to Prof. Carlos Rossa Junior for his assistance during the experimental stages of this study.

connective tissue graft in the treatment of human gingival recession. J Periodontol. 1999;70(2):123-30.

4. Cortellini P, DeSanctis M, Pini Prato G, Baldi C, Clauser C. Guided tissue regeneration procedure using a fibrin-fibronectin system in surgically induced recession in dogs. Int J Periodontics Restorative Dent. 1991;11(2):150-63.

5. Harris RJ. A comparison of 2 root coverage techniques: guided tissue regeneration with bioabsorbable matrix style membrane versus a connective tissue graft without vertical inci- 
sions. Results of a series of consecutive cases. J Periodontol. 1998;69(12):1426-34.

6. Leknes KN, Amarante ES, Price DE, Boe OE, Skavland RJ, Lie T. Coronally positioned flap procedures with or without a biodegradable membrane in the treatment of human gingival recession. A 6-year follow-up study. J Clin Periodontol. 2005;32(5):518-29.

7. Paolantonio M. Treatment of gingival recessions by combined periodontal regenerative technique, guided tissue regeneration, and subpedicle connective tissue graft. A comparative clinical study. J Periodontol. 2002;73(1):53-62.

8. Trombelli L, Scabbia A, Tatakis DN, Calura G. Subpedicle connective tissue graft versus guided tissue regeneration with bioabsorbable membrane in the treatment of human gingival recession defects. J Periodontol. 1998;69(11):1271-7.

9. Trombelli L, Tatakis DN, Scabbia A, Zimmerman GJ. Comparison of mucogingival changes following treatment with coronally positioned flap and guided tissue regeneration procedures. Int J Periodontics Restorative Dent. 1997;17(5):44855.

10. Wang HL, Bunyaratavej P, Labadie M, Shyr Y, MacNeil RL. Comparison of 2 clinical techniques for treatment of gingival recession. J Periodontol. 2001;72(10):1301-11.

11. Bowers GM, Chadroff B, Carnevale R, Mellonig J, Corio $\mathrm{R}$, Emerson $\mathrm{J}$ et al. Histologic evaluation of new attachment apparatus formation in humans. Part I. J Periodontol. 1989;60(12):664-74.

12. da Silva Pereira SL, Sallum AW, Casati MZ, Caffesse RG, Weng D, Nociti Jr FH et al. Comparison of bioabsorbable and non-resorbable membranes in the treatment of dehiscence-type defects. A histomorphometric study in dogs. J Periodontol. 2000;71(8):1306-14.

13. Harris RJ. Human histologic evaluation of a bone graft combined with GTR in the treatment of osseous dehiscence defects: a case report. Int J Periodontics Restorative Dent. 2000;20(5):510-9.

14. Harris RJ. Histologic evaluation of root coverage obtained with GTR in humans: a case report. Int J Periodontics Restorative Dent. 2001;21(3):240-51.

15. Lee EJ, Meraw SJ, Oh TJ, Giannobile WV, Wang HL. Comparative histologic analysis of coronally advanced flap with and without collagen membrane for root coverage. J Periodontol. 2002;73(7):779-88.

16. Parma-Benfenati S, Tinti C. Histologic evaluation of a new attachment utilizing a titanium-reinforced barrier membrane in a mucogingival recession defect. A case report. J Periodontol. 1998;69(7):834-9.

17. Sallum EA, Pimentel SP, Saldanha JB, Nogueira-Filho GR, Casati MZ, Nociti FH et al. Enamel matrix derivative and guided tissue regeneration in the treatment of dehiscence-type defects: a histomorphometric study in dogs. J Periodontol. 2004;75(10):1357-63.

18. Weng D, Hurzeler MB, Quinones CR, Pechstadt B, Mota L, Caffesse RG. Healing patterns in recession defects treated with ePTFE membranes and with free connective tissue grafts. A histologic and histometric study in the beagle dog. J Clin Periodontol. 1998;25(3):238-45.

19. Dodge JR, Greenwell H, Drisko C, Wittwer JW, Yancey J, Rebitski G. Improved bone regeneration and root coverage using a resorbable membrane with physically assisted cell migration and DFDBA. Int J Periodontics Restorative Dent. 2000;20(4):398-411.

20. Duval BT, Maynard JG, Gunsolley JC, Waldrop TC. Treatment of human mucogingival defects utilizing a bioabsorbable membrane with and without a demineralized freeze-dried bone allograft. J Periodontol. 2000;71(11):1687-92.

21. Kimble KM, Eber RM, Soehren S, Shyr Y, Wang HL. Treatment of gingival recession using a collagen membrane with or without the use of demineralized freeze-dried bone allograft for space maintenance. J Periodontol. 2004;75(2):210-20.

22. Rosetti EP, Marcantonio RAC, Rossa Jr C, Chaves ES, Goissis G, Marcantonio Jr E. Treatment of gingival recession: comparative study between subepithelial connective tissue graft and guided tissue regeneration. J Periodontol. 2000;71(9):1441-7.

23. Wang HL, Kimble K, Eber R. Use of bone grafts for the enhancement of a GTR-based root coverage procedure: a pilot case study. Int J Periodontics Restorative Dent. 2002;22(2):11927.

24. de Oliveira CA, Spolidorio LC, Cirelli JA, Marcantonio RA. Acellular dermal matrix allograft used alone and in combination with enamel matrix protein in gingival recession: histologic study in dogs. Int J Periodontics Restorative Dent. 2005;25(6):595-603.

25. Cirelli JA, Marcantonio Jr E, Marcantonio RAC, Lia RCC, Goissis G, Rossa C Jr. Evaluation of anionic collagen membranes in the treatment of class II furcation lesions: a histometric analysis in dogs. Biomaterials. 1997;18(18):1227-34.

26. Pitaru S, Tal H, Soldinger M, Azar AO, Noff M. Collagen membranes prevent the apical migration of epithelium during periodontal wound healing. J Periodontal Res. 1987;22(4):3313. 